\title{
Dietary Practices and Nutritional Status of Urban Vulnerable: A Cross-Sectional Study on Waste Collectors of Dhaka City in Bangladesh
}

Asit Biswas ${ }^{1}$, M. A. Rifat ${ }^{1 *}$, Hazera Binte Sufian ${ }^{1}$, MD Khurshidul Zahid PhD ${ }^{1}$

${ }^{1}$ Institute of Nutrition and Food Science, University of Dhaka, Dhaka-1000, Bangladesh

*Corresponding Author: M. A. Rifat, Research Assistant, Institute of Nutrition and Food Science, University of Dhaka, Dhaka-1000, Bangladesh. E-mail: rifatahmed011@gmail.com ORCID ID: https://orcid.org/0000-0003-0562-9791

\section{Abstract}

\section{Purpose}

The socioeconomic conditions of urban waste collectors are vulnerable. However, their nutrition vulnerability remains undocumented. Here we focused on dietary practices and the nutritional status of waste collectors of Dhaka city in Bangladesh.

\section{Methods}

A cross-sectional design was employed that included 130 waste collectors from 15 different sites of Dhaka city. The 24-hours recall method, body mass index (BMI) and BMI for age Z-score were used to determine dietary practices and nutritional status respectively. Chi-square test, Fisher's exact test, and multinomial logistic regression analysis were used to observe the associations and their risk factors.

\section{Results}

The majority (58.5\%) of the waste collectors were normal by BMI whereas 36.2\%, 4.5\%, and 0.8\% were underweight, overweight, and obese respectively. The prevalence of underweight was higher among males and respondents less than 18-years old $(\mathrm{P}<0.001)$. The dietary pattern of the respondents was poor. Meals were mainly rice and vegetable-based. Consumption of meats, eggs and fruits was low. Only $18.4 \%$ and $16.92 \%$ respondents were found to consume meat and eggs at least once a day, respectively. In addition, 78.5\% consumed insufficient foods in their main meals, 9.2\% had skipped meals and $13.1 \%$ consumed stale food and food waste regularly. Consumption of less than three main meals a day and food of poor dietary quality were risk factors of underweight.

\section{Conclusion}

Findings demonstrated that waste collectors in Dhaka city had poor nutritional status which was primarily associated with inadequate dietary intake. Increased quality and quantity of foods in the diet, which could be achieved through appropriate health and nutritional support, are needed to overcome the situation.

Key words: Waste collector, Dhaka city, Underweight, Nutritional status, Cross-sectional 


\section{Introduction}

Rapid urbanization in recent decades leads to huge waste heaps, mainly generated from households, and the food, industry and medical sectors, in the big cities of Bangladesh, and it requires extensive effort for waste management (Dewan et al., 2012). Household waste generation in Dhaka city was found to be associated with household size, income, environmental concern and willingness to pay for waste management system (Afroz et al., 2009; Afroz et al., 2011). Waste collectors are the frontline workers who primarily collect waste materials for further processing. In Dhaka city, waste is collected by both formal and informal waste collectors (Chowdhury \& Afza, 2006; Zahur, 2007). Household waste collectors (HWCs) are part of the formal waste management system, whereas street waste collectors (SWCs) belong to the informal waste management system mainly performed by one of the most vulnerable urban population groups locally named Tokai.

Waste collectors throughout the world live with poor socioeconomic status, work in unhygienic environments, and struggle for maintaining a minimal standard of life (Walker, 2008; Samson, 2009). Moreover, they are unrewarded and largely ignored by urban policy makers (De Bercegol et al., 2017). Waste collectors are usually migrants to urban areas, earn less than other population groups, and often stay homeless which collectively causes them to be highly vulnerable with respect to health and nutrition (Bagchi et al., 2017). They have been found to have poor knowledge and practice about solid waste handling which increases the chance of their exposure to hazardous materials or chemicals (Azfar et al., 2018; Nandimath et al., 2019). They suffer from various health problems such as gastrointestinal infections, loss of appetite, respiratory symptoms, and musculoskeletal disorders (Ivens et al., 1997; Thorn et al., 1998; El-Wahab et al., 2014; Patil et al., 2017; Habybabady et al., 2018).

It was estimated that only $37 \%$ wastes in Dhaka city were properly collected due to lack of a proper waste collection system; illegal disposal of wastes has been responsible for critical environmental and health issues (Enayetullah et al., 2005). In Bangladesh, no previous study depicted food consumption and nutritional status of the waste collectors in Bangladesh. Despite performing an important role, they are one of the most vulnerable urban population groups in Bangladesh. Waste collectors are deprived of policy benefits; thus, this study focused on the household waste collectors (HWCs) and street waste collectors (SWCs) through a nutritional lens. It is hoped that its findings would be useful for policy makers to design and implement effective policy interventions targeting their nutrition and well-being.

\section{Methods}

\section{Study design}

The study employed a cross-sectional approach. Data were collected through direct interviews and household visits from the chosen waste collectors. The STROBE guidelines (contact author for supplementary file) were followed at the various stages of this study (Von Elm et al., 2014). Sample size, sampling technique, and study period

Preliminary information about both formal and informal waste collectors, their collection sites, and their residence was gathered contacting with Dhaka City Corporation (DCC) and Rajdhani Unnayan Kartripakkha (RAJUK), Bangladesh. Based on this, 15 wards were randomly selected from 93 wards of Dhaka City Corporation. One site was chosen from each ward. Thus, a total of 15 sites were randomly selected, meeting the criteria of a probability sample of Dhaka city. There 
was lack of information about the number of people engaged in informal waste management system. Therefore, no sample size calculation was carried out. We followed systematic random selection of the respondents, including every second waste collector we met at each sampling site. A pilot data collection was conducted in one sampling site to test the measurement instruments and protocols (questionnaire, anthropometric measurement tools, 24h-recall method) and to estimate the number of respondents likely to be encountered at each sampling site/area. Respondents who were interviewed during the pilot data collection were not included in the final samples. At least 8 respondents were included in the study from each sampling site. Thus, a total of 130 waste collectors were included for face-to-face interviews. Data were collected during the period of January 2013 to March 2013.

\section{Data collection and analysis tools}

Data were collected by direct interviewing of the participants at their workplaces. Data were checked, validated, and entered into SPSS (version18.0 SPSS Inc, Chicago, IL, USA) for statistical analysis. In some cases, data credibility, regarding dietary intake, was confirmed by household visits and also observing the meals.

\section{Assessing the nutritional status}

Nutritional status of the adults (>18 years) was assessed by body mass index (BMI) as per standard (WHO, 2004). For the subjects less than 18 years, the BMI for age Z-score was used. Body weight and height was measured by digital bath scale and height measuring tape respectively while clothed. These measurements were taken at the place of the interview. The measuring tools were calibrated and standardized regularly before every measurement. Body weight and height were measured to the nearest values of $\pm 100 \mathrm{~g}$ and $\pm 1 \mathrm{~cm}$ respectively.

\section{Dietary assessment}

The dietary pattern was assessed by the 24-hour recall method through a semi-structured questionnaire (Rutishauser, 2005). Questionnaires also included questions regarding respondents' food preferences, food purchasing priority, and indicators of food security, including food consumption sufficiency, intake of stale food and food waste (food which had been thrown away), and number of meals a day.

\section{Association measurement}

Since our endogenous variable BMI has more than two levels (underweight, normal, overweight, and obesity), we applied multinomial logistic regression for measuring the dependence between BMI and dietary practices. While performing the statistical analysis, the gender and age of the respondents were controlled for. All the explanatory variables of dietary practices are binary (Yes/No): insufficiency of foods in meals, status of stale or food leftover consumption, consumption of less than three meals a day, habit of drinking carbonated beverages, habit of tobacco smoking, and habit of smoking cannabis.

Differences in nutritional status by age, sex, and dietary composition in last 24 hours were assessed by Pearson Chi-square $\left(\chi^{2}\right)$ test, and Fisher's exact test was used when cell sizes were small. All the statistical tests were performed at 95\% confidence interval (CI) or at $\alpha=0.05$.

\section{Ethics approval}

The research was designed based on the ethical guideline of Bangladesh Medical Research Council (BMRC) and Declaration of Helsinki. Participants were clearly explained about the study objectives and written consent was obtained. 


\section{Results}

\section{Sample characteristics, nutritional status and dietary practices}

The average age of the respondents was 27.8 years; $25.4 \%$ were below 18 years of age, while $73.8 \%$ were male. $47.7 \%$ were street waste collectors, $15.4 \%$ were household waste collectors and $36.9 \%$ collected waste from both households and streets. The environment on which the waste collectors work was very unhealthy and unhygienic. Street waste collectors were exposed to industrial, medical, and sewerage waste.

$36.2 \%$ were underweight, $58.5 \%$ were normal, $4.5 \%$ were overweight, and $0.8 \%$ was obese (Table 1). Underweight was higher among males (39.6\%), respondents $<18$ years old (87.9\%) and street waste collectors (43.5\%).

Table 1: Nutritional status of the waste collectors by sex, age, and types $(n=130)$

\begin{tabular}{llllll}
\hline Sample characteristics & Underweight & Normal & Overweight & Obesity & $\begin{array}{l}\text { Sample } \\
\text { size (n) }\end{array}$ \\
\hline $\begin{array}{l}\text { Sex } \\
\quad \text { Male }\end{array}$ & $39.6(38)$ & $58.3(56)$ & $1.0(1)$ & $1.0(1)$ & 96 \\
$\quad \begin{array}{l}\text { Female } \\
\text { *Age }\end{array}$ & $26.5(9)$ & $58.9(20)$ & $14.7(5)$ & $0.0(0)$ & 34 \\
$\quad<18$ years & & & & \\
$\quad \begin{array}{l}\text { 18 years } \\
\text { Type }\end{array}$ & $187.9(29)$ & $12.1(4)$ & $0.0(0)$ & $0.0(0)$ & 33 \\
$\quad$ HWCs & & $74.2(72)$ & $6.2(6)$ & $1.0(1)$ & 97 \\
$\quad$ SWCs & $25.0(5)$ & $70.0(14)$ & $5.0(1)$ & $0.0(0)$ & 20 \\
$\quad$ Both & $43.5(27)$ & $51.6(32)$ & $4.8(3)$ & $0.0(0)$ & 62 \\
Total & $31.2(15)$ & $62.5(30)$ & $4.2(2)$ & $2.1(1)$ & 48 \\
\hline
\end{tabular}

Date is presented as \% (n), $n=$ number of samples

${ }^{*}$ P-value less than 0.05 calculated by Pearson Chi-square $\left(\chi^{2}\right)$ test and Fisher's exact test between normal and all other categories combine (underweight, overweight, and obesity). Here, for age, P-value was $<0.001$

HWCs (Household waste collectors) and SWCs (Street waste collectors)

The dietary pattern, based on a 24-h recall, shows that frequency of rice and vegetable consumption was higher than the other food items such as meats, eggs and fruits. Almost all (99.2\%) the respondents consumed vegetable at least one time a day whereas fruits, eggs and meats were the least consumed of the daily food items (Table 2).

Table 2: Consumption pattern of different food items in 24-h recall period $(n=130)$

\begin{tabular}{lllllllll}
\hline $\begin{array}{l}\text { Consumption } \\
\text { pattern }\end{array}$ & Rice & Bread & Fish & Meat & Egg & Legumes & Vegetables & Fruit \\
\hline $\begin{array}{l}\text { Meal time } \\
\quad \text { Breakfast }\end{array}$ & $59.3(77)$ & $39.2(51)$ & $22.3(29)$ & $3.9(5)$ & $8.5(11)$ & $22.3(29)$ & $75.4(98)$ & $6.2(8)$ \\
$\quad$ Lunch & $67.7(88)$ & $18.5(24)$ & $35.4(46)$ & $5.4(7)$ & $6.2(8)$ & $22.3(29)$ & $67.0(87)$ & $9.2(12)$ \\
$\quad \begin{array}{l}\text { Dinner } \\
\text { Frequency }\end{array}$ & $86.5(112)$ & $10.3(13)$ & $44.6(58)$ & $10.7(14)$ & $6.9(9)$ & $29.6(38)$ & $80.7(105)$ & $0.0(0)$ \\
$\quad$ & & & & & & & & \\
$\quad \begin{array}{l}\text { Tne time } \\
\text { Tho times }\end{array}$ & $16.2(21)$ & $51.5(67)$ & $42.3(55)$ & $15.4(20)$ & $13.9(18)$ & $31.5(41)$ & $16.9(22)$ & $15.4(20)$ \\
Three times & $32.3(42)$ & $6.9(9)$ & $25.3(33)$ & $2.3(3)$ & $1.5(2)$ & $15.4(20)$ & $40.8(53)$ & $0.0(0)$ \\
\hline
\end{tabular}

Data are presented as \% (n), $n=$ number of samples

Multiple counts were considered for consumption of different food items in different meal times 
Regarding food preferences, fish came first as the most preferred food item for most of the respondents (68.2\%), but only $24.6 \%$ respondents were able to prioritize fish for purchasing occasionally from the market. Similarly, $15.4 \%$ of respondents said that they prefer to consume meat (any kind) whereas only $1.5 \%$ was able to purchase meat at least occasionally. A significant difference was found between respondents' food preference and food purchasing $(\mathrm{P}<0.000)$ (Table 3).

Table 3: Food preference and food purchasing priority from the market $(n=130)$

\begin{tabular}{llllll}
\hline Category & Fish & Meat & Vegetable & Pulse & $\begin{array}{l}\text { Rice and } \\
\text { wheat }\end{array}$ \\
\hline Food preference & $68.2(86)$ & $15.4(20)$ & $16.9(22)$ & $1.5(2)$ & $0.0(0)$ \\
Food purchasing & $24.6(32)$ & $1.5(2)$ & $27.7(36)$ & $10.0(13)$ & $36.2(47)$ \\
\hline Da
\end{tabular}

Data are presented as \% (n), $n=$ number of samples

The dietary assessment also explored other food habits. A total of $73.0 \%$ respondents used to drink tea of which $66.2 \%$ preferred milk tea, $1.5 \%$ preferred raw tea, and $5.38 \%$ preferred both categories. For $47.6 \%$ cases, frequency of drinking tea was 3-5 cups daily. A total of $66.2 \%$ respondents smoked cigarettes, $8.4 \%$ smoked cannabis, 53.0\% consumed carbonated beverages, and $19.2 \%$ used betel leaf on a daily basis. Smoking of cannabis was found to be associated with the smoking of tobacco. Consumption of all these items (except for cannabis) varied significantly by type of waste collectors (street, household, and both) $(\mathrm{P}<0.05)$.

\section{Association between nutritional status and dietary practices}

Multinomial logistic regression model was used to examine the impact of dietary practices on nutritional status. Average BMI was low for the respondents with food insufficiency in the meals, consumption of stale food and food waste, consumption of less than 3 meals a day, drinking of carbonated beverage, smoking tobacco, and smoking cannabis. The largest difference in body mass index was largest $(\mathrm{P}<0.05)$ among those who did vs those who did not smoke cannabis (Figure 1).

As shown in (Table 4), only two of the associations between BMI and dietary practices remained statistically significant in the multinomial logistic regression. First, for each unit increase in "less than three meals a day", there is 2.10 units $(b=2.10, p<0.026)$ increase for a case to fall into the "underweight" category (relative to the "normal" category). Second, for the respondents who eat insufficient foods in the main meals, overweight decreases by 2.76 units ( $b=-2.76$, $\mathrm{p}<0.019$ ) for one-unit decrease in the sufficiency of foods in their main meals.

\section{Discussion}

No prior study has examined the nutritional status, the dietary pattern, and the relationship between these among the waste collectors in Bangladesh. There are other anthropological methods of estimating nutritional status such as hip circumference, waist circumference, triceps skin fold (TSF). In our study, BMI was used because of convenience of data collection and the availability of standard references. BMI differs by age, sex, physical activity level, diseases status and so on. That is why we utilized a probability sample and uniform data collection techniques for minimizing bias. 
Figure 1: Body mass index (BMI) of the respondents as categorized by dietary practices $(n=130)$

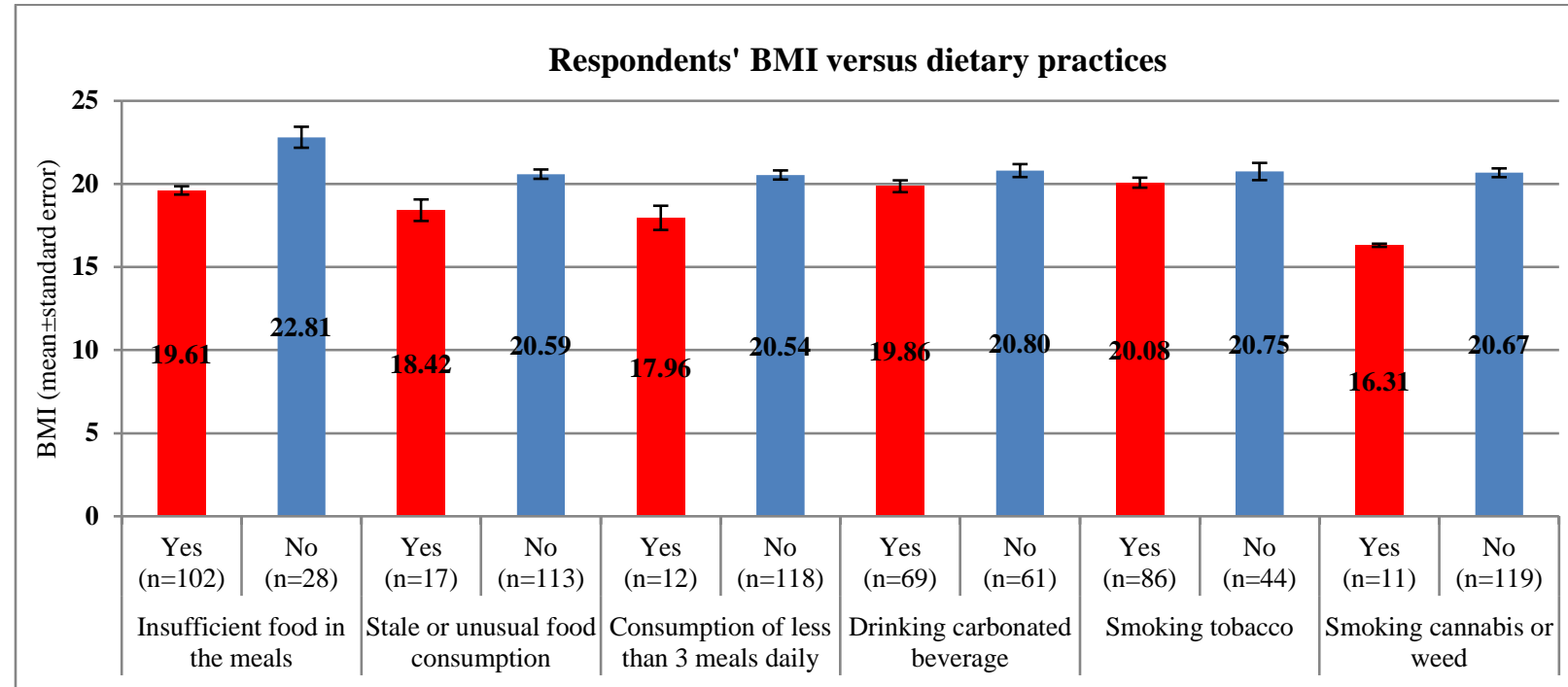

We found that $36.2 \%(n=47)$ of the waste collectors were underweight. This can be compared to Bangladesh Demographic and Health Survey 2011 data showing that the underweight prevalence among the people living in urban areas in Bangladesh was 18.8 (95\% CI: 16.2-21.8) (Biswas T et al., 2017). Food security in Bangladesh showed excellent progress in last decade, but insecurity still exists among the socio-economically vulnerable population groups (Faridi \& Wadood, 2010). According to the Food Security and Nutrition Surveillance Project (FSNSP), there was a sharp decrease in food insecurity during the year 2010-2014 in terms of indicators such as consumption of unusual foods such as food leftovers (18\% to 1\%), consumption of smaller meals (50\% to 15\%), and skipping meals (15\% to 4\%) (HKI, 2010; HKI, 2014). In our study, Figure 1 shows that $13.1 \%(n=17)$ of waste collectors consumed unusual foods (leftover, food waste or stale foods), $78.5 \%(n=102)$ consumed smaller meals, and 9.2\% $(n=12)$ consumed less than 3 meals a day (skipping meals), a worse scenario than the national picture in each case.

Waste collectors' meals were mainly rice and vegetable based with low amount of meats and eggs. Fish was the most consumed as protein source. The gap between food preference and food purchasing priority was significant $(\mathrm{P}<0.000)$. Poor socio-economic status may lead to poor dietary consumption and subsequently poor nutritional status (Darmon \& Drewnowski, 2008). Additionally, homelessness and dependency on street vended foods leave them, especially SWCs, in serious food insecurity. It was found that their average daily income was only BDT 150 (approximately 1.9 USD) (Rifat et al., 2018). Waste collectors in other countries such as India and Nepal were found to smoke cigarette, tobacco and to drink alcohol (Salve \& Bansod, 2017). We found $66.2 \%$ waste collectors regularly smoked tobacco which was higher than the daily smoking 
Table 4: Results of the multinomial logistic regression for measuring the association between body mass index (BMI) and dietary practices of the waste collectors $(n=130)$

\begin{tabular}{|lccccc|}
\hline \multicolumn{1}{|c}{ Body Mass Index (BMI) } & Coefficient & $\begin{array}{c}\text { Standard } \\
\text { error }\end{array}$ & P-value & 95\% CI \\
\hline Underweight & & & & & \\
Consumes insufficient foods in meals & 1.28 & 0.68 & 0.058 & -0.05 & 2.62 \\
Consumes stale foods or food leftover & -0.35 & 0.75 & 0.64 & -1.82 & 1.12 \\
Less than three meals a day & 2.10 & 0.94 & $0.026^{*}$ & 0.26 & 3.95 \\
Drinks carbonated beverage & 0.50 & 0.44 & 0.249 & -0.35 & 1.36 \\
Smokes tobacco & -0.23 & 0.46 & 0.614 & -1.13 & 0.67 \\
Smokes cannabis & 18.79 & 3257.81 & 0.995 & -6366.40 & 6403.99 \\
Constant & -2.06 & 0.74 & 0.005 & -3.52 & -0.61 \\
Normal & base outcome & & & & \\
Overweight & & & & & \\
Consumes insufficient foods in meals & -2.76 & 1.17 & $0.019 *$ & -5.05 & -0.46 \\
Consumes stale foods or food leftover & -14.69 & 5165.45 & 0.998 & -10138.78 & 10109.40 \\
Less than three meals a day & -13.17 & 6793.69 & 0.998 & -13328.56 & 13302.21 \\
Drinks carbonated beverage & -2.06 & 1.19 & 0.084 & -4.39 & 0.28 \\
Smokes tobacco & -1.14 & 0.99 & 0.25 & -3.08 & 0.80 \\
Smokes cannabis & 3.97 & 10604.00 & 1.00 & -20779.50 & 20787.43 \\
Constant & -0.03 & 0.74 & 0.965 & -1.49 & 1.43 \\
Obesity & & & & & 639.43 \\
Consumes insufficient foods in meals & -17.26 & 3246.63 & 0.996 & -6380.54 & 6346.01 \\
Consumes stale foods or food leftover & 0.20 & 10396.34 & 1.00 & -20376.25 & 20376.64 \\
Less than three meals a day & 11.57 & 77100.44 & 1.00 & -151102.50 & 151125.70 \\
Drinks carbonated beverage & -16.53 & 2863.78 & 0.995 & -5629.44 & 5596.39 \\
Smokes tobacco & -16.34 & 2900.50 & 0.996 & -5701.21 & 5668.53 \\
Smokes cannabis & 24.17 & 78375.33 & 1.00 & -153588.70 & 153637.00 \\
Constant & -1.05 & 1.14 & 0.354 & -3.28 & 1.17 \\
\hline
\end{tabular}

*Significantly associated

prevalence among men (38.0\%) in Bangladesh and Nepalese waste workers, who showed a smoking prevalence of 40.3\% (Ng et al., 2014; Black et al., 2019). In addition, 8.4\% waste collectors smoked cannabis and 19.2\% consumed betel leaf regularly. This status was higher than the available reference data for Bangladeshi population (3\% smoked cannabis and 17.5\% consumed betel leaf) (Khan et al., 2006). We found poor nutritional status was associated $(\mathrm{P}<0.05)$ with cannabis smoking. Hunger is an environmental stressor, linked to cannabis use in adolescents in both Asia (Peltzer \& Pengpid, 2017) and Africa (Peltzer \& Pengpid, 2018). This may mean that its use is often a result rather than a cause of hunger.

The solid waste management system in Bangladesh is becoming challenging due to the increasing generation of waste and a limitation of funds, (Bhuiyan, 2010; Guerrero et al., 2013). Yet urban residents were willing to pay to receive better waste collection services (Afroz et al., 
2009). One possibility is to raise collaborative funds for street waste collectors through nongovernmental organizations or building public-private partnership (Matter et al.,2013). Waste collectors are an un-united and distressed segment of population. Proper and effective utilization of waste collectors might be a sustainable solution for improving urban environment as well as their living standard (Chowdhury \& Afza, 2006; Ezeah et al., 2013).

Limitations of the study include a lack of background information about the target group; thus, determining the sample size through calculation was not possible. Waste collectors have a low illiteracy rate and a highly itinerant. Thus, it was not possible to consider using more timeconsuming dietary assessment procedures.

On the other hand, the study has created the beginning of an evidence base regarding nutrition and diet of the waste collectors in Dhaka of Bangladesh. Further research could be carried out to observe the underlying factors of their poor nutritional and dietary status.

\section{Conclusions}

Nutritional status of the waste collectors is not satisfactory, indicating a higher prevalence of underweight than that the overall urban population. They consume poor diet characterized by inadequate food consumption, skipping meal, and consumption of stale or leftover foods. In addition, a higher rate of tobacco and cannabis smoking than is seen in the general population was found. This study will give scope to the policy makers to consider nutritional issues of both the formal and informal waste collectors in Bangladesh. Effective interventions could include food aid, food ration shops and other safety net programs. Improving nutrition for waste workers will in the long run promote sustainable environmental cleanliness for all.

\section{List of abbreviations}

BDT: Bangladeshi Taka

BMI: Body Mass Index

FSNSP: Food Security and Nutrition Surveillance Project

HWCs: Household Waste Collectors

SPSS: Statistical Package for the Social Sciences

STROBE: STrengthening the Reporting of OBservational studies in Epidemiology

SWCs: Street Waste Collectors

TSF: Triceps Skin Fold

USD: United States Dollar

\section{Acknowledgement}

University Grants Commission (UGC) of Bangladesh provided partial financial support to this study. Technical assistance was provided by Institute of Nutrition and Food Science (INFS), University of Dhaka, Bangladesh.

\section{Conflict of Interest}

No conflict of interest is declared by the authors.

\section{Availability of data and materials}

Available based on request to the corresponding author. 


\section{References}

Afroz R, K Hanaki, K Hasegawa-Kurisu. 2009. Willingness to pay for waste management improvement in Dhaka city, Bangladesh. Journal of Environmental Management. 90(1): 492-503. https://doi.org/10.1016/j.jenvman.2007.12.012

Afroz R, K Hanaki, R Tudin. 2011. Factors affecting waste generation: a study in a waste management program in Dhaka City, Bangladesh. Environmental Monitoring and Assessment. 179(1-4):509-519. https://doi.org/10.1007/s10661-010-1753-4

Azfar ZM, Nazri SM, Rusli AM, Maizurah O, Zahiruddin WM, Azwany YN, et al. 2018. Knowledge, attitude and practice about leptospirosis prevention among town service workers in northeastern Malaysia: a cross sectional study. Journal of Preventive Medicine and hygiene. 59(1), E92. https://doi.org/10.15167/2421-4248/jpmh2018.59.1.776

Bagchi D, Mitra IK. 2017. Life, Labour, Recycling: A Study of Waste Management Practices in Contemporary Kolkata. In Accumulation in Post-Colonial Capitalism (pp. 149-163). Springer, Singapore. https://doi.org/10.1007/978-981-10-1037-8

Bhuiyan SH. 2010. A crisis in governance: Urban solid waste management in Bangladesh. Habitat International. 34(1):125-133. https://doi.org/10.1016/j.habitatint.2009.08.002

Biswas T, Garnett SP, Pervin S, Rawal LB. 2017. The prevalence of underweight, overweight and obesity in Bangladeshi adults: Data from a national survey. PloS one. 12(5): e0177395. https://doi.org/10.1371/journal.pone.0177395

Black M, J Karki, ACK Lee, P Makai, YR Baral, EI Kritsotakis, et al. 2019. The health risks of informal waste workers in the Kathmandu Valley: a cross-sectional survey. Public Health. 166:10-18. https://doi.org/10.1016/j.puhe.2018.09.026

Chowdhury TA, Afza SR. 2006. Waste management in Dhaka City-A theoretical marketing model. BRAC University Journal. 3(2):101-111. http://hdl.handle.net/10361/579

Darmon N, A Drewnowski. 2008. Does social class predict diet quality? American Journal of Clinical Nutrition. 87(5):1107-1117. https://doi.org/10.1093/ajcn/87.5.1107

De Bercegol R, Cavé J, Nguyen Thai Huyen A. 2017. Waste Municipal Service and Informal Recycling Sector in Fast-Growing Asian Cities: Co-Existence, Opposition or Integration? Resources. 6(4):70. https://doi.org/10.3390/resources6040070

Dewan AM, MH Kabir, K Nahar, MZ Rahman. 2012. Urbanisation and environmental degradation in Dhaka Metropolitan Area of Bangladesh. International Journal of Environment and Sustainable Development. 11(2):118-147. https://doi.org/10.1504/IJESD.2012.049178

El-Wahab EWA, Eassa SM, Lotfi SE, El Masry SA, Shatat HZ, Kotkat AM. 2014. Adverse health problems among municipality workers in Alexandria (Egypt). International 
Journal of Preventive Medicine. 5(5):545.

https://www.ncbi.nlm.nih.gov/pmc/articles/PMC4050674/

Enayetullah I, Sinha AMM, Khan SSA. 2005. Urban solid waste management scenario of Bangladesh: problems and prospects. Waste Concern Technical Documentation.

Ezeah C, JA Fazakerley, CL Roberts. 2013. Emerging trends in informal sector recycling in developing and transition countries. Waste Management. 33(11):2509-2519. https://doi.org/10.1016/j.wasman.2013.06.020

Faridi R, SN Wadood. 2010. An Econometric Assessment of Household Food Security in Bangladesh. The Bangladesh Development Studies. 33(3):97-111. https://bids.org.bd/uploads/publication/BDS/33/33-3/04.pdf

Guerrero LA, G Maas, W Hogland. 2013. Solid waste management challenges for cities in developing countries. Waste Management. 33(1):220-232. https://doi.org/10.1016/j.wasman.2012.09.008

Habybabady RH, Sis HN, Paridokht F, Ramrudinasab F, Behmadi A, Khosravi B, et al. 2018. Effects of Dust Exposure on the Respiratory Health Symptoms and Pulmonary Functions of Street Sweepers. The Malaysian Journal of Medical Sciences: MJMS. 25(6): 76. https://doi.org/10.21315/mjms2018.25.6.8

HKI and JPGSPH. 2011. State of Food security and nutrition in Bangladesh: 2010. Dhaka, BD: Helen Keller International (HKI) and James P Grant School of Public Health (JPGSPH). http://sph.bracu.ac.bd/index.php/publications/fsnspreport

HKI and JPGSPH. 2016. State of Food security and nutrition in Bangladesh: 2014. Dhaka, BD: Helen Keller International (HKI) and James P Grant School of Public Health (JPGSPH). http://sph.bracu.ac.bd/index.php/publications/fsnspreport

Ivens UI, Hansen J, Breum NO, Ebbehøj N, Nielsen M, Poulsen OM, et al. 1997. Diarrhoea among waste collectors associated with bioaerosol exposure. Annals of Agricultural and Environmental Medicine. 4:63-68.

Khan MM, K Aklimunnessa, MA Kabir, M Kabir, M Mori. 2006. Tobacco consumption and its association with illicit drug use among men in Bangladesh. Addiction. 101(8): 11781186. https://doi.org/10.1111/j.1360-0443.2006.01514.x

Matter A, M Dietschi, C Zurbrügg. 2013. Improving the informal recycling sector through segregation of waste in the household-The case of Dhaka Bangladesh. Habitat International. 38:150-156. http://dx.doi.org/10.1016/j.habitatint.2012.06.001

Nandimath PT, Rao NSN, Subramaniyan U, Mishra B, Kalidindi BR, Shrivastava R, et al. 2019. Knowledge and Practices of Municipal Solid Waste Workers: Findings from Focused 
Group Discussions. In Waste Management and Resource Efficiency (pp. 287-298).

Springer, Singapore. https://doi.org/10.1007/978-981-10-7290-1_25

Ng M, MK Freeman, TD Fleming, M Robinson, L Dwyer-Lindgren, B Thomson, et al. 2014. Smoking prevalence and cigarette consumption in 187 countries, 1980-2012. JAMA. 311(2): 183-192. https://doi.org/10.1001/jama.2013.284692

Patil PV, Kamble RK. 2017. Occupational Health Hazards in Sanitary Workers of Chandrapur City, Central India. International Journal of Environment. 6(3):15-24. https://doi.org/10.3126/ije.v6i3.18095

Peltzer, K. and Pengpid, S., 2017. Cannabis and amphetamine use among adolescents in five Asian countries. Central Asian Journal of Global Health. 6(1). https://doi.org/10.5195/cajgh.2017.288

Peltzer, K. and Pengpid, S., 2018. Cannabis and amphetamine use and associated factors among school-going adolescents in nine African countries. Journal of Child \& Adolescent Substance Abuse. 27(2):112-118. https://doi.org/10.1080/1067828X.2017.1420512

Rifat MA, Biswas A, Sufian HB, Azad F, Zahid MDK. 2018. Socio-Economic Status, Hygiene Practices and Microbial Exposure of the Waste Collectors of Dhaka City in Bangladesh. Global Journal of Health Science. 10(12):96-103. https://doi.org/10.5539/gjhs.v10n12p96

Rutishauser IH. 2005. Dietary intake measurements. Public Health Nutrition. 8(7a):1100-1107. https://doi.org/10.1079/PHN2005798

Salve P, Bansod DW. 2017. Occupational Morbidity among Municipal Solid Waste Loaders in Mumbai. Social Science Spectrum. 2(3):195-202. http://socialspectrum.in/index.php/sp/article/view/78

Samson M. 2009. Refusing to be Cast Aside: Waste Pickers Organising Around the World, Published by Women in Informal Employment: Globalizing and Organizing (WIEGO), Cambridge, MA, USA. https://www.wiego.org/publications/refusing-be-cast-aside-wastepickers-organising-around-world

Thorn J, Beijer L, Rylander R. 1998. Airways inflammation and glucan exposure among household waste collectors. American Journal of Industrial Medicine. 33(5):463-470. https://doi.org/10.1002/(SICI)1097-0274(199805)33:5<463::AID-AJIM5>3.0.CO;2-T

Von Elm E, Altman DG, Egger M, Pocock SJ, Gøtzsche PC, Vandenbroucke JP and Strobe Initiative. 2014. The Strengthening the Reporting of Observational Studies in Epidemiology (STROBE) Statement: guidelines for reporting observational studies. International Journal of Surgery. 12(12):1495-1499.

https://doi.org/10.1016/j.ijsu.2014.07.01 3 
Walker, D. 2008. The World's Scavengers: Salvaging for Sustainable Consumption and Production: Martin Medina. Taylor \& Francis. https://doi.org/10.1080/09614520802387304

Who EC. 2004. Appropriate body-mass index for Asian populations and its implications for policy and intervention strategies. Lancet. 363(9403):157-163. https://doi.org/10.1016/S0140-6736(03)15268-3

Zahur M. 2007. Solid waste management of Dhaka city: public private community partnership. BRAC University Journal. 4(2). http://hdl.handle.net/10361/399 